\title{
The Effects of Biological and Social Risk Factors on Special Education Placement: Birth Weight and Maternal Education as an Example
}

\author{
Holly A. Hollomon, \\ Dionne R. Dobbins, and
}

\author{
Keith G. Scott \\ University of Miami
}

\begin{abstract}
The effects of birth weight $(B W)$ and maternal education (ME) on special education placement at age 10 were studied. Epidemiologic methods quantified risk to the individual and to the population using an electronically linked, county-wide database of birth and school records. A dose-response relationship was found between BW and ME. High ME may serve as a buffer for children with a biological risk for developmental delays. A clinically important finding was that children born with very low BW to mothers with low ME were at a high level of individual risk for receiving special education services. However, such children accounted for a small number of the overall cases. The largest percentage of children receiving special education services had the single risk factor of low ME. From a public policy standpoint, children born to mothers with low levels of education are an important group to target for early intervention.
\end{abstract}

The authors would like to thank the Dade County Department of Health Office of Vital Statistics Public Health Statistics for providing the birth records and the Florida Department of Education Bureau of Instructional Support and Community Services for providing the school records necessary for this study. We also acknowledge the work of Richard Urbano, PhD, Carol Boussy, PhD, Angelika Claussen, $\mathrm{PhD}$, and Elyse Hurtado, $\mathrm{PhD}$ in the preparation and linkage of the data sets.

Requests for reprints should be sent to Holly A. Hollomon, University of Miami, Department of Psychology, Annex, P.O. Box 249229, Coral Gables, FL 33124-0721; E-mail: hhollomo@ child.psy.miami.edu. 
Some individual characteristics, experiences, or environmental conditions leave children vulnerable for developmental disorders. These conditions can be referred to as risk factors. Risk models can be developed that assume a person's level of risk represents his/her need for services. In other words, risk can be thought of as a proxy for need (Backett, Davies, \& Petros-Barvazian, 1984). Information derived from risk analyses can provide insight into the areas requiring prevention and intervention services, in turn guiding research and informing public policy.

The major method of risk quantification developed by epidemiologists has only recently been applied to the study of child development. Concerned with identifying the distribution of the determinants and consequences of disease in human populations (Hennekens \& Buring, 1987), epidemiology has investigated infectious disease with a single causative agent. As the chief causes of death have shifted, chronic disease has become an important focus of public health (Pearce, 1996; Susser \& Susser, 1996). Accompanying this shift, a methodology for identifying multiple risk factors has developed in epidemiology. It is this multiple risk factor methodology that can be utilized to understand multiple influences on child development.

The emerging application of epidemiology to child development, termed developmental epidemiology, is defined as "the study of the distribution of behavioral outcomes in infancy and childhood and the indicators of their occurrence" (Scott, Shaw, \& Urbano, 1994, p. 352). The major goal of this field is to estimate the risk of a poor developmental outcome associated with exposure to various risk factors. This knowledge can be used to plan prevention and intervention services (Scott, 1995).

\section{BIRTH WEIGHT AS A RISK FACTOR}

Being born low birth weight (LBW $<2500$ grams) has been identified as a potential risk factor for poor child outcomes (Calame et al., 1986; Drillien, Thomson, \& Burgoyne, 1980; McCormick, 1989). Goldenberg and Bronstein (1994) report that babies born LBW have a higher mortality rate than their normal birth weight (NBW > 2500 grams) peers. However, more LBW babies are surviving past infancy due to advances in medical technology (Dunn, 1986; Hack, Klein, \& Taylor, 1995; Hoy, Bill, \& Sykes, 1988). Therefore, the long-term outcomes of children born LBW need to be investigated.

As birth weight decreases, developmental outcomes worsen (Calame et al., 1986; Grunau, 1986; Hack et al., 1994; Klebanov, Brooks-Gunn, \& McCormick, 1994; Lagerstrom, Bremme, Eneroth, \& Magnusson, 1991). The majority of very low birth weight (VLBW $<1500$ grams) children exhibit few problems (Drillien et al., 1980). However, compared to their NBW peers, they are at increased risk for many poor outcomes, including physical and cognitive delays (Hack et al., 1994; Kitchen, 1980; Klein, Hack, \& Breslau, 1989; NobleJamieson, Lukeman, Silverman, \& Davies, 1982; Rickards et al., 1993), higher 
rates of academic problems (Grunau, 1986; Kitchen et al., 1980; McCormick, 1989), lower scores on standardized tests of achievement/academic grades (Lagerstrom et al., 1991; Schraeder, Heverly, O’Brien, \& McEvoy-Shields, 1992; Nielson \& Sapp, 1991; Saigal, Szatmari, Rosenbaum, Campbell, \& King, 1991), and increased risk for learning disabilities and special educational services (Grunau, 1986; Saigal et al., 1991; Siegel, 1994).

Biological and social factors can be confounded in explaining the sequelae of children born VLBW because it is more prevalent in minority and other high-risk populations (Goldenberg \& Bronstein, 1994). Of all live births in the White population, approximately $6 \%$ are LBW and less than $1 \%$ are VLBW. These percentages are almost doubled in minority populations (Bennett, 1988).

Because VLBW is confounded by other risk factors, the accumulation of social factors may be more important or as important as birth weight status alone in explaining developmental outcomes (Kopp, 1983; Schraeder et al., 1992; Drillien et al., 1980; Ramey, Stedman, Borders-Patterson, \& Mengel, 1978). Zigler (1995) argues that because adverse outcomes are typically found in children from lower economic strata, the identification of social factors associated with these outcomes may clarify the nature of the problem. Thus, it is necessary to investigate both the biological risk factors (e.g., birth weight) as well as the socioenvironmental risk factors of children born VLBW.

\section{MATERNAL EDUCATION AS A RISK FACTOR}

Investigators studying the school performance of children born NBW have found that social-structural variables, such as socioeconomic stress and maternal education, account for large amounts of variance in children's success (Schraeder et al., 1992). Socioenvironmental variables can be used to predict school outcomes and identify at-risk populations. They can be seen as markers for the specific pathways through which their influence is manifested.

Low maternal education can be seen as an indicator of other factors associated with socioeconomic status (SES). The number of years of education completed may be a marker for other variables that are important in determining child outcomes. Variables correlated with amount of educational experience, such as home environment, nutrition, and cognitive stimulation (Satcher, 1995), are those that contribute directly to the determination of developmental outcomes. Furthermore, maternal education may be a useful indicator of important environmental and social factors when in-depth measures of family environments are not feasible.

Maternal education level has been identified as a prominent risk factor for negative child outcomes. Cognitive deficits have been associated with lower maternal education (Zigler, 1995). The Metropolitan Atlanta Study found that low maternal education was a significant risk factor for mild mental retardation (Drews, Yeargin-Allsopp, Decoufle, \& Murphy, 1995; Kramer, Allen, \& Gergen, 1995; Yeargin-Allsopp, Drews, Decoufle, \& Murphy, 1995). 
The question remains, however, does maternal education interact with other known risk factors? Among infants born VLBW, parental education level has been associated with the severity of disability at ages 8 and 11 (Hunt, Cooper, \& Tooley, 1988). In addition, the outcomes of some LBW babies may be moderated by high maternal education (Brooks-Gunn, Gross, Kraemer, Spiker, \& Shapiro, 1992; Gross, Brooks-Gunn, \& Spiker, 1992; Liaw \& Brooks-Gunn, 1993; McCormick, Brooks-Gunn, Workman-Daniels, Turner, \& Peckham, 1992). McCormick et al. (1992) found that among infants weighing at least 1,000 grams born to mothers who had more than a high school education, no differences in IQ could be attributed to LBW alone.

\section{RATIONALE FOR CURRENT STUDY}

In summary, both birth weight and maternal education are important variables to consider when assessing child outcomes. In the past, LBW has been confounded with low SES in the prediction of child outcomes (Siegel, 1994). Therefore, the current study was designed to examine the separate and joint effects of birth weight and maternal education on the special education placement of 10-year-old children.

While profound disabilities may be recognized early, assessment of less severe handicaps requires a long follow-up period (Kitchen et al., 1980). The identification of educational handicaps peaks at age 10 (Carran, Scott, Shaw, \& Beydouin, 1989). Thus, the present study examines the long-term effects of maternal education and birth weight on special education placements at age 10 .

Previous studies of VLBW have had several problems due to the low prevalence of the condition ( $<1 \%$ of the population), including small samples and inability to examine long-term outcomes. Subject attrition due to death or loss of contact compounds the problem of small sample sizes (Siegel, 1994). The present study attempts to address these problems by electronically linking extant databases of birth and school records. County-wide databases are used to provide a large sample of children from many catchment areas. Additionally, information about subject status may be obtained electronically, thus eliminating problems of attrition and noncompliance.

Finally, because previous studies have focused on the educational outcomes of individuals born VLBW, they have provided little information on the overall contribution of VLBW to the population receiving special education services. Epidemiologic methods are used to assess risk to the individual separately from risk to the community. The potential risk each child has of being placed in special education given one or both risk factors can be found. In addition, the potential decrease in special education placements in the population that would occur by targeting one or both risk factors for prevention can be quantified. 


\section{METHOD}

\section{Participants}

The sample consisted of children from Dade County, Florida, whose 1979/80 birth records were linked to their 1990/91 school records using an automated computer data linkage system. There were 27,951 children representing $93 \%$ of the school records in the linked sample. Maternal education data were missing for $0.2 \%$ of the sample so analyses were based on the 27,908 children with complete data. The sample was composed of $51 \%$ males and $49 \%$ females with a mean age of 10 . Approximately $39 \%$ of the sample were African American, $32 \%$ Hispanic, $28 \%$ Caucasian, and $1 \%$ other.

\section{Procedure}

Extant databases of birth records and school records for children in Dade County, Florida were linked using a computer algorithm. The algorithm used phonetic code for child's last name, first name, date of birth, gender, and mother's name in determining probable matches. The linkage methodology used in the current study has been validated previously (Boussy, 1992). The electronically linked data were compared to a manually linked subset indicating sensitivity and specificity rates of 97\% (Boussy, 1993).

Birth records consisted of all birth records in Dade County during the years 1979 to 1980 . The school record data set consisted of all school records from Dade County Public Schools during the 1990/91 school year. The birth/school linkage contained information on each subject at birth and in school at age 10 . After the linkage was complete, all personally identifying information was removed from the data to maintain the subjects' confidentiality.

\section{Variables}

Risk factors were retrieved from the birth records and included birth weight and maternal education. Birth weight (BW) was divided into three levels: very low (VLBW < 1500 grams); low (LBW = 1500-2499 grams); and normal (NBW $\geq 2500$ grams). Maternal education (ME) was divided into three levels: low (LME $<12$ years), average (AME = 12 years), and high ( $\mathrm{HME}>12$ years). The outcome of interest was special education placement at age 10 and was retrieved from the school records.

\section{Analytical Methods}

Epidemiologic methods were used to analyze the data in terms of risk to the individual and the community. An important measure of individual risk, the relative risk, is the rate of disability among those who are exposed to a given risk factor relative to the rate of disability among those who are not exposed 
TABLE 1

Percentages of Children Born Very Low Birth Weight in Exceptionality Categories as Defined by Dade County

\begin{tabular}{lrr}
\hline Category & $N$ & Percentage \\
\hline Learning disabled & 24 & $10.8 \%$ \\
Speech impaired & 8 & $3.6 \%$ \\
Educable mentally handicapped & 5 & $2.3 \%$ \\
Emotionally handicapped & 5 & $2.3 \%$ \\
Physically impaired & 4 & $1.8 \%$ \\
Hard of hearing & 2 & $.9 \%$ \\
Visually impaired & 2 & $.9 \%$ \\
Profoundly mentally handicapped & 2 & $.9 \%$ \\
Trainable mentally handicapped & 1 & $.5 \%$ \\
Severely emotionally disturbed & 1 & $.5 \%$ \\
Deaf & 1 & $.5 \%$ \\
Language impaired & 0 & $.0 \%$ \\
Autistic & 0 & $.0 \%$ \\
Total & 55 & $25.0 \%$ \\
\hline
\end{tabular}

$N=222$.

(Hennekens \& Buring, 1987). The nonexposed group is termed the referent group and is assigned a risk value of one. The risk an exposed group has of developing an outcome relative to this referent group is then determined. Risk estimates and their $95 \%$ confidence intervals were calculated using the epidemiologic statistical software package True Epistat (Gustafson, 1991). Confidence intervals were listed in parentheses following relative risk values.

As a community risk measure, attributable risk was calculated to estimate the proportion of cases in the population that may be prevented if the risk factor was eliminated. The attributable risk takes into account the frequency of the risk factor in the community as well as the frequency of the unwanted outcome when the risk factor is present and absent (Hennekens \& Buring, 1987). It is essential to determine the relative impact of risk factors on the population to guide future prevention and intervention efforts.

\section{RESULTS}

Descriptive Analyses

Descriptive analyses were conducted using the Statistical Package for Social Sciences (SPSS, 1994). Less than $1 \%$ of the sample was born VLBW (0.8\%). Of those children, $25 \%$ were receiving some form of special education service at age 10 . The exceptionality category most common in this group was learning disabled, at $10.8 \%$. The percentage of children born VLBW in each exceptionality category can be found in Table 1 . Approximately one third of the sample (31.1\%) had mothers with less than 12 years of education. Of those children, $15.8 \%$ were receiving some kind of special education service at the time of 
TABLE 2

Percentages of Children in Exceptionality Categories as Defined by Dade County Whose Mother Had Low Maternal Education

\begin{tabular}{lrr}
\hline Category & $N$ & Percentage \\
\hline Learning disabled & 890 & $10.2 \%$ \\
Speech impaired & 141 & $1.6 \%$ \\
Emotionally handicapped & 130 & $1.5 \%$ \\
Educable mentally handicapped & 125 & $1.4 \%$ \\
Trainable mentally handicapped & 33 & $.4 \%$ \\
Severely emotionally disturbed & 18 & $.2 \%$ \\
Physically impaired & 10 & $.1 \%$ \\
Profoundly mentally handicapped & 12 & $.1 \%$ \\
Visually impaired & 5 & $.1 \%$ \\
Deaf & 4 & $.0 \%$ \\
Language impaired & 3 & $.0 \%$ \\
Hard of hearing & 2 & $.0 \%$ \\
Autistic & 2 & $.0 \%$ \\
Total & 1375 & $15.8 \%$ \\
\hline
\end{tabular}

$N=8693$.

follow-up, with the largest percentage classified as having a learning disability $(10.2 \%)$. The percentage of children in each disability category whose mother had less than 12 years of education can be found in Table 2.

\section{Preliminary Analyses}

The sample was divided into nine mutually exclusive and exhaustive categories of risk based on level of ME and BW (see Table 3). Risk ratios were calculated

TABLE 3

Preliminary Analyses: Nine Mutually Exclusive Categories of Risk and the Prevalence in Each Category

\begin{tabular}{lrr}
\hline Risk Group & $N$ & Prevalence \\
\hline VLBW and LME & 83 & $.3 \%$ \\
VLBW and AME & 93 & $.3 \%$ \\
VLBW and HME & 45 & $.2 \%$ \\
LBW and LME & 718 & $2.6 \%$ \\
LBW and AME & 745 & $2.7 \%$ \\
LBW and HME & 410 & $1.5 \%$ \\
NBW and LME & 7892 & $28.3 \%$ \\
NBW and AME & 10519 & $37.7 \%$ \\
NBW and HME & 7403 & $26.5 \%$ \\
\hline
\end{tabular}

Note. VLBW = very low birth weight; $\mathrm{LME}=$ low maternal education; AME $=$ average maternal education; $\mathrm{HME}=$ high maternal education; $\mathrm{LBW}=$ low birth weight; NBW $=$ normal birth weight.

$N=27,908(0.2 \%$ of the cases were missing information on ME). 


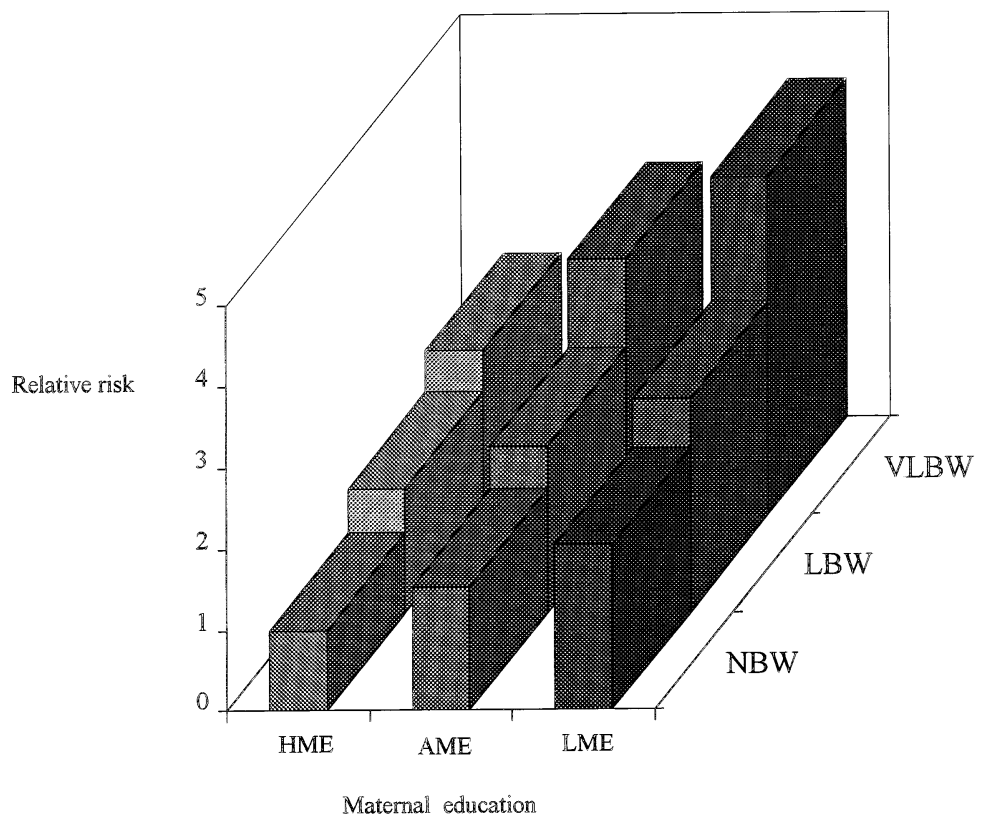

FIGURE 1. Dose-response relation between birth weight and maternal education for special needs placement at age 10.

to determine the joint effects of $\mathrm{ME}$ and $\mathrm{BW}$ on the need for special education placement at age 10. The referent group in the preliminary analyses was composed of children born NBW to mothers who had more than 12 years of education.

A clear dose-response trend emerged between $\mathrm{BW}$ and $\mathrm{ME}$ in the risk for special education placement (see Fig. 1). Specifically, as BW and ME decreased, risk of placement in special education at age 10 increased. Individuals born VLBW to mothers with LME had over 4 times the risk of being placed in special education, as compared with the referent group. Table 4 contains exact relative risks and confidence intervals associated with each level of risk.

Secondary Analyses

For the second set of analyses, the sample was divided into four mutually exclusive and exhaustive groups (see Table 5). The separate and joint risks of being born VLBW and having a mother who did not complete high school were identified. The referent group consisted of children born weighing at least 1500 grams and having mothers with at least 12 years of education. Risk ratios were calculated to determine the risk of needing special education services at age 10 on three groups: VLBW only, LME only, and both risk factors (see Fig. 2).

For the individual child, having both risk factors meant being 3.10 (2.25- 
TABLE 4

Relative Risk (and Confidence Intervals) of Special Education for All Levels of Maternal Education and Birth Weight

\begin{tabular}{llcc}
\hline & \multicolumn{3}{c}{ Maternal Education } \\
\cline { 2 - 4 } & \multicolumn{1}{c}{ High } & Average & Low \\
\hline NBW & 1.0 & $1.54(1.40-1.70)$ & $2.05(1.86-2.25)$ \\
LBW & $1.53(1.16-2.03)$ & $2.07(1.72-2.49)$ & $2.65(2.24-3.13)$ \\
VLBW & $2.08(1.05-4.13)$ & $3.17(2.18-4.60)$ & $4.19(3.02-5.82)$ \\
\hline
\end{tabular}

Note . NBW = normal birth weight; $\mathrm{LBW}=$ low birth weight; VLBW = very low birth weight. $N=27,908$.

4.27) times more likely than the referent group to be identified as needing special education services at age 10. Children with VLBW as their only risk factor were $2.08(1.50-2.88)$ times more likely to need special education services at age 10. Finally, children having mothers with LME as their only risk factor were receiving special education services 1.55 (1.45-1.65) times more often than the referent group.

Attributable risk was calculated for each of the three groups described above to estimate the proportion of cases that may be prevented by the elimination of the exposure (Northridge, 1995). Nineteen percent of the cases of special education can be attributed to LME alone, while $0.8 \%$ are associated with the risk factor of being born VLBW alone. One percent of special education cases were attributable to the joint occurrence of VLBW and LME (see Fig. 3). In theory, eliminating both risk factors would reduce the population receiving special education services by approximately $21 \%$.

\section{DISCUSSION}

The results of the present study emphasize the importance of including social factors in the investigation of BW outcomes. A dose-response trend emerged

TABLE 5

Secondary Analyses: Four Mutually Exclusive Categories of Risk and the Prevalence in Each Category

\begin{tabular}{lrr}
\hline Risk Group & $N$ & Prevalence \\
\hline VLBW only & 138 & $.5 \%$ \\
LME only & 8610 & $30.8 \%$ \\
Both & 83 & $.3 \%$ \\
Neither & 19,077 & $68.4 \%$ \\
\hline
\end{tabular}

Note. VLBW $=$ very low birth weight LME $=$ low maternal education. $N=27,908$. 


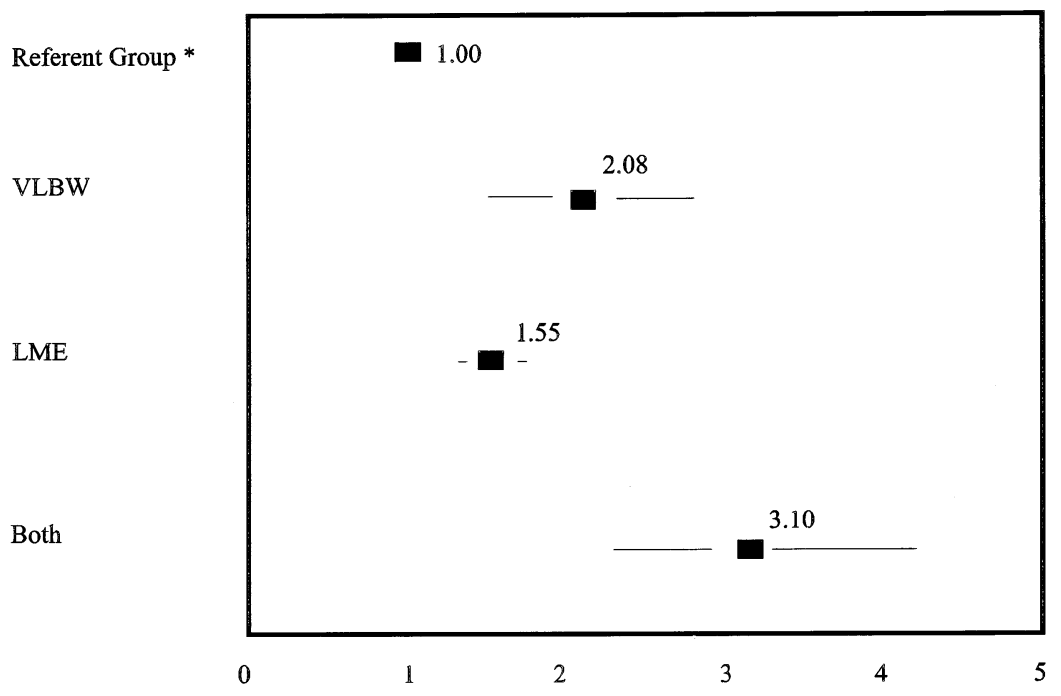

Relative Risk

FIGURE 2. Separate and joint effects of very low birth weight (VLBW) and low maternal education (LME) on the special education placement of individuals.

that provides researchers and public policy makers with information on the joint effects of BW and ME. The data show that the effects of BW vary depending upon levels of ME. The lower the ME, the worse are the educational outcomes of children born VLBW. In other words, being highly educated may buffer against the negative outcomes associated with being born VLBW.

The second set of analyses shows the importance of looking at individual and community risks separately. The combination of VLBW and LME is associated with the highest risk of special education placement to the individual child. However, only $1 \%$ of special education placements in the population can be attributed to the combination of those risk factors. On the other hand, LME is associated with almost one fifth of the children receiving special education services. Because the attributable fraction accounts for the prevalence of the risk factor and LME is highly prevalent, this risk factor was associated with the highest percentage of special education placements.

In the current study, approximately one third of the children were born to mothers who had less than 12 years of education. Other research has found a high prevalence of LME in large scale, big city studies. For example, $22 \%$ of the sample had mothers with LME in the Metropolitan Atlanta Developmental Disabilities Study (Satcher, 1995). By targeting ME, prevention efforts may 


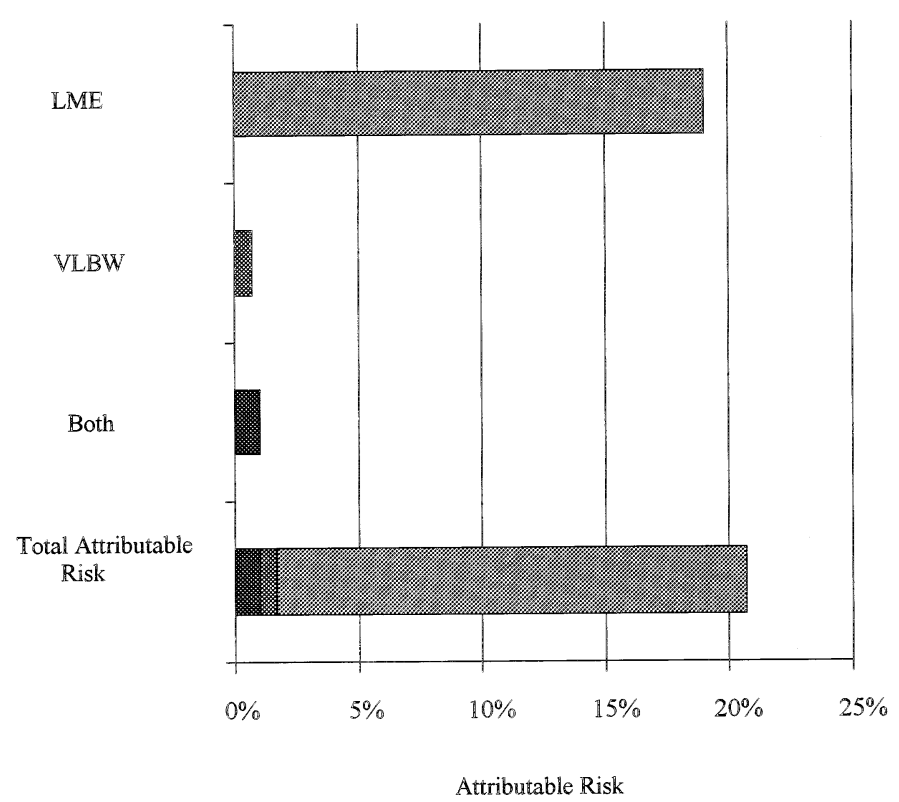

FIGURE 3. Separate and joint effects of very low birth weight (VLBW) and low maternal education (LME) on the population of children placed in special education.

have a greater impact on the overall prevalence of special education placements at a population level.

Being born VLBW is a detrimental risk for the individual child, making it a clinically important risk factor. Children with the risk factor of VLBW should be screened for potential developmental disabilities. However, less than $1 \%$ of children receiving special education services can be attributed to being born VLBW because it is a low prevalence condition. From a public policy standpoint, the findings from this research suggest that LME should be targeted to effect the greatest reduction in the number of children requiring special education services.

By targeting $\mathrm{ME}$ for prevention and early intervention, many children born VLBW will also receive services due to the co-occurrence of biological and social risk factors. Being born VLBW is more prevalent in minority and lower SES communities that also frequently have lower education levels. For example, the current study indicates that targeting ME would affect $31 \%$ of the overall sample, including $37.4 \%$ of the children born VLBW. Many children with the highest risk of being placed in special education (those with both risk factors) will also be targeted for early intervention. In this manner, intervention dollars are spent both on the children who are at the most risk and the children most likely to contribute to the cases of special education in the population. 


\section{REFERENCES}

Backett, E. M., Davies, A. M., \& Petros-Barvazian, A. (1984). Public Health Papers: Vol. 76. The risk approach in health care. Geneva: World Health Organization.

Bennett, F. C. (1988). Neurodevelopmental outcome in low birth weight infants: The role of developmental intervention. Clinics in Critical Care Medicine, 13, 221-249.

Boussy, C. A. (1992). Developmental disabilities surveillance studies in Florida. Record linkage methodology: The key to epidemiologic research. (Contract No. LCA83). Tallahassee, FL: Department of Health and Rehabilitative Services, Interagency Office of Disability Prevention.

Boussy, C. A. (1993). A comparison of hand and computer-linked records (Doctoral dissertation, University of Miami, 1992). Dissertation Abstracts International, 53(8-B), 4389.

Brooks-Gunn, J., Gross, R. T., Kraemer, H. C., Spiker, D., \& Shapiro, S. (1992). Enhancing the cognitive outcomes of low birth weight, premature infants: For whom is the intervention most effective? Pediatrics, 89, 1209-1215.

Calame, A., Fawer, C. L., Claeys, V., Arrazola, L., Ducret, S., \& Jaunin, L. (1986). Neurodevelopmental outcome and school performance of very-low-birth-weight infants at 8 years of age. European Journal of Pediatrics, 145, 461-466.

Carran, D. T., Scott, K. G., Shaw, K., \& Beydouin, S. (1989). The relative risk of educational handicaps in two birth cohorts of normal and low birthweight disadvantaged children. Topics in Early Childhood Special Education, 9, 14-31.

Drews, C. D., Yeargin-Allsopp, M., Decoufle, P., \& Murphy, C. (1995). Variation in the influence of selected sociodemographic risk factors for mental retardation. American Journal of Public Health, 85, 329-334.

Drillien, C. M., Thomson, A. J. M., \& Burgoyne, K. (1980). Low-birthweight children at early school-age: A longitudinal study. Developmental Medicine and Child Neurology, 22, 26-47.

Dunn, H. G. (Ed.). (1986). Sequelae of low birthweight: The Vancouver study. London: Mac Keith Press.

Goldenberg, R., \& Bronstein, J. (1994). Preventing low birth weight. In Wallace, H. M., Nelson, R. P., \& Sweeney, P. J. (Eds.), Maternal and child health practices (4th ed., pp. 260-278). Oakland, CA: Third Party Publishing Co.

Gross, R. T., Brooks-Gunn, J., Spiker, D. (1992). Efficacy of comprehensive early interventions for low-birthweight premature infants and their families: The infant health and development program. In I. E. Siegel (Series Ed.) and S. L. Friedman \& M. Sigman (Vol. Eds.), The Psychological Development of Low-Birthweight Children: Annual Advances in Applied Developmental Psychology Volume 6, (pp. 411-433). Norwood, NJ: Ablex Publishing Corporation.

Grunau, R. V. E. (1986). Educational achievement. In H. G. Dunn (Ed.), Sequelae of low birthweight: The Vancouver study (pp. 179-204). Philadelphia: Lippincott.

Gustafson, T. L. (1991). True epistat manual (4th ed.) Richardson, TX: Epistat services.

Hack, M., Klein, N. K., \& Taylor, H. G. (1995). Long-term developmental outcomes of low birth weight infants. The Future of Children, 5, 176-196.

Hack, M., Taylor, H. G., Klein, N., Eiben, R., Schatschneider, C., \& Mercuri-Minich, N. (1994). School-age outcomes in children with birth weights under $750 \mathrm{~g}$. The New England Journal of Medicine, 331, 753-759.

Hennekens, C. H., \& Buring, J. (1987). Epidemiology in medicine. Boston MA: Little Brown and Company.

Hoy, E. A., Bill, J. M., \& Sykes, D. H. (1988). Very low birthweight: A long-term developmental impairment? International Journal of Behavioral Development, 11, 37-67.

Hunt, J. V., Cooper, B. A. B., \& Tooley, W. H. (1988). Very low birth weight infants at 8 and 11 years of age: Role of neonatal illness and family status. Pediatrics, 82, 596-603.

Kitchen, W. H., Ryan, M. M., Rickards, A., McDougall, A. B., Billson, F. A., Keir, E. H., \& Naylor, F. D. (1980). A longitudinal study of very low-birthweight infants. IV: An overview of performance at eight years of age. Developmental Medicine and Child Neurology, 22, 172-188. 
Klebanov, P. K., Brooks-Gunn, J., \& McCormick, M. C. (1994). School achievement and failure in very low birth weight children. Journal of Developmental and Behavioral Pediatrics, 15, $248-257$.

Klein, N. K., Hack, M., \& Breslau, N. (1989). Children who were very low birth weight: Development and academic achievement at nine years of age. Journal of Developmental and Behavioral Pediatrics, 10, 32-37.

Kopp, C. B. (1983). Risk factors in development. In P. H. Mussen (Series Ed.), M. M. Haith, \& J. J. Campos (Vol. Eds.), Handbook of child psychology: Vol. 2. Infancy and developmental psychobiology (4th ed., pp. 1081-1188). New York: John Wiley \& Sons.

Kramer, R., Allen, L., \& Gergen, P. (1995). Health and social characteristics and children's cognitive functioning: Results from a national cohort. American Journal of Public Health, 85, 312-318.

Lagerstrom, M., Bremme, K., Eneroth, P., \& Magnusson, D. (1991). School performance and IQ test scores at age 13 as related to birth weight and gestational age. Scandinavian Journal of Psychiatry, 32, 316-324.

Liaw, F., \& Brooks-Gunn, J. (1993). Patterns of low-birth-weight children's cognitive development. Developmental Psychology, 29, 1024-1035.

McCormick, M. C. (1989). Long-term follow-up of infants discharged from neonatal intensive care units. Journal of the American Medical Association, 261, 1767-1772.

McCormick, M. C., Brooks-Gunn, J., Workman-Daniels, K., Turner, J, \& Peckham, G. J. (1992). The health and development status of very low-birth-weight children at school age. Journal of the American Medical Association, 267, 2204-2208.

Nielson, S., \& Sapp, G. (1991) Bender-Gestalt developmental scores: Predicting reading and math achievement. Psychological Reports, 69, 39-42.

Noble-Jamieson, C. M., Lukeman, D., Silverman, M., \& Davies, P. A. (1982). Low birth weight children at school age: Neurological, psychological, and pulmonary function. Seminars in Perinatology, 6, 266-273.

Northridge, M. E. (1995). Annotation: Public health methods - attributable risk as a link between causality and public health action. American Journal of Public Health, 85, 1202-1203.

Pearce, N. (1996). Traditional epidemiology, modern epidemiology, and public health. American Journal of Public Health, 86, 678-683.

Ramey, C. T., Stedman, D. J., Borders-Patterson, A., \& Mengel, W. (1978). Predicting school failure from information available at birth. American Journal of Mental Deficiency, 82, 525-534.

Rickards, A. L., Kitchen, W., Doyle, L., Ford, G., Kelly, E., \& Callanan, C. (1993). Cognition, school performance and behavior in very low birth weight and normal birth weight children at 8 years of age: A longitudinal study. Journal of Developmental and Behavioral Pediatrics, 14, 363-368.

Saigal, S., Szatmari, P., Rosenbaum, P., Campbell, D., \& King, S. (1991). Cognitive abilities and school performance of extremely low birth weight children and matched term control children at age 8 years: A regional study. Journal of Pediatrics, 118, 751-760.

Satcher, D. (1995). Annotation: The sociodemographic correlates of mental retardation. American Journal of Public Health, 85, 304-306.

Schraeder, B. D., Heverly, M., O’Brien, C., \& McEvoy-Shields, K. (1992). Finishing first grade: A study of school achievement in very low birth weight children. Nursing Research, 41, 354-361.

Scott, K. G. (1995). Risk as a proxy for need. Paper presented at the Biennial Meeting of the Society for Research in Child Development, Indianapolis, IN.

Scott, K. G., Shaw, K., \& Urbano, J. C. (1994). Developmental epidemiology. In S. Friedman \& C. Haywood (Eds.), Developmental follow-up (pp. 351-373). New York: Academic Press.

Siegel, L. S. (1994). The long-term prognosis of pre-term infants: Conceptual, methodological, and ethical issues. Human Nature, 5, 103-126.

SPSS. (1994). Version 4.0 for UNIX System. [Computer software]. Chicago, IL: SPSS Inc. 
Susser, M., \& Susser, E. (1996). Choosing a future for epidemiology: I. Eras and paradigms. American Journal of Public Health, 86, 668-673.

Yeargin-Allsopp M., Drews, C. D., Decoufle, P., \& Murphy, C. (1995). Mild mental retardation in black and white children in metropolitan Atlanta: A case-control study. American Journal of Public Health, 85, 324-328.

Zigler, E. (1995). Editorial: Can we "cure" mild mental retardation among individuals in the lower socioeconomic stratum? American Journal of Public Health, 85, 302-304. 